\title{
The detection of specific IgM antibodies following infection with rubella virus
}

\author{
J. R. PATTISON ${ }^{1}$ AND JENNIFER E. MACE
}

From the Department of Virology, Institute of Pathology, Middlesex Hospital Medical School, London

SYNOPSIS A gel filtration technique using Sephadex G-200 has been used for the detection of specific IgM in sera from (a) 45 cases of clinical rubella in which diagnostic rises of rubella haemagglutination-inhibiting (HAI) antibody could be demonstrated; (b) 70 cases with clinical evidence of rubella in which a rising titre could not be demonstrated because the first serum sample already had high titre HAI antibodies; and (c) 100 patients in whom rubella was not suspected. The results indicate that the high specificity and sensitivity of the method described make it an appropriate technique for use in the routine diagnosis of acquired rubella.

The fractionation of immunoglobulins in whole human serum by gel filtration requires relatively inexpensive equipment and simple techniques (Pattison and Mace, 1973). However, only limited studies of the application of such techniques to the diagnosis of rubella have been described (Gupta, Peterson, Stout, and Murphy, 1971; Bürgin-Wolff, Hernandez, and Just, 1971; Pattison and Mace, 1973). Here we report the results of the application of a gel filtration technique using Sephadex G-200 to 115 cases of acquired rubella and a similar number of patients in whom recent rubella was not suspected.

\section{Materials and Methods}

RUBELLA HAEMAGGLUTINATIONINHIBITION (HAI) TESTS

Rubella HAI tests incorporating overnight incubation of virus/serum mixtures were performed as previously described (Pattison and Mace, 1973a) using the rubella haemagglutinin supplied by the Central Public Health Laboratory, Colindale, London, NW9 5HT.

FRACTIONATION OF SERA

The gel filtration technique using Sephadex G-200 (Pharmacia (GB) Ltd, Uxbridge Road, London,

'Present address: Department of Virology, Institute of Pathology, London Hospital Medical College, Turner Street, London E1 2AD

Received for publication 3 December 1974.
W5 5SS) was based on that previously described (Pattison and Mace, 1973). In all gel filtration procedures $0.1 \mathrm{M}$ Tris buffered $0.9 \% \mathrm{NaCl}$ pH 7.5 with $0.1 \%$ sodium azide is now used in place of the phosphate-buffered saline originally described (Pattison and Mace, 1973). Fresh, unheated sera are pretreated by adding an equal volume of a mixture of $\mathrm{MnCl}_{2}(0.2 \mathrm{M})$ and heparin (1000 units $/ \mathrm{ml}$ ), incubating at $4^{\circ}$ for $20 \mathrm{~min}$ before centrifuging to deposit the precipitate. This pretreatment procedure removes both the $\beta$-lipoprotein nonspecific inhibitors (Schmidt and Lennette, 1970) and the 'heavy' inhibitors recently described by Al-Nakib, Best, and Banatvala (1974). Samples, $0.4-0.5 \mathrm{ml}$, of the supernatant are loaded on to columns of Sephadex G-200 and eluted at a rate of 15 to $20 \mathrm{ml} /$ hour. The preparation of the column is as previously described (Pattison and Mace, 1973) except that gel beds of $42 \times 2.5 \mathrm{~cm}$ (Pharmacia chromatographic column K $25 / 45)$ or $33 \times 2.6$ $\mathrm{cm}$ (Pharmacia chromatographic column K26/40) have been used. With the former a $0.5 \mathrm{ml}$ sample is applied and $5 \mathrm{ml}$ fractions of eluate are collected and with the latter $0.4 \mathrm{ml}$ samples are applied and $4 \mathrm{ml}$ fractions are collected. With low titre sera (HAI titre 1 in 20) 0.8 or $1 \mathrm{ml}$ samples are applied. After fractionation the gamma globulin-containing fractions are selected and rubella HAI tests performed on them as previously described (Pattison and Mace, 1973).

Figure 1a illustrates a typical result found after fractionating and testing an early convalescent 


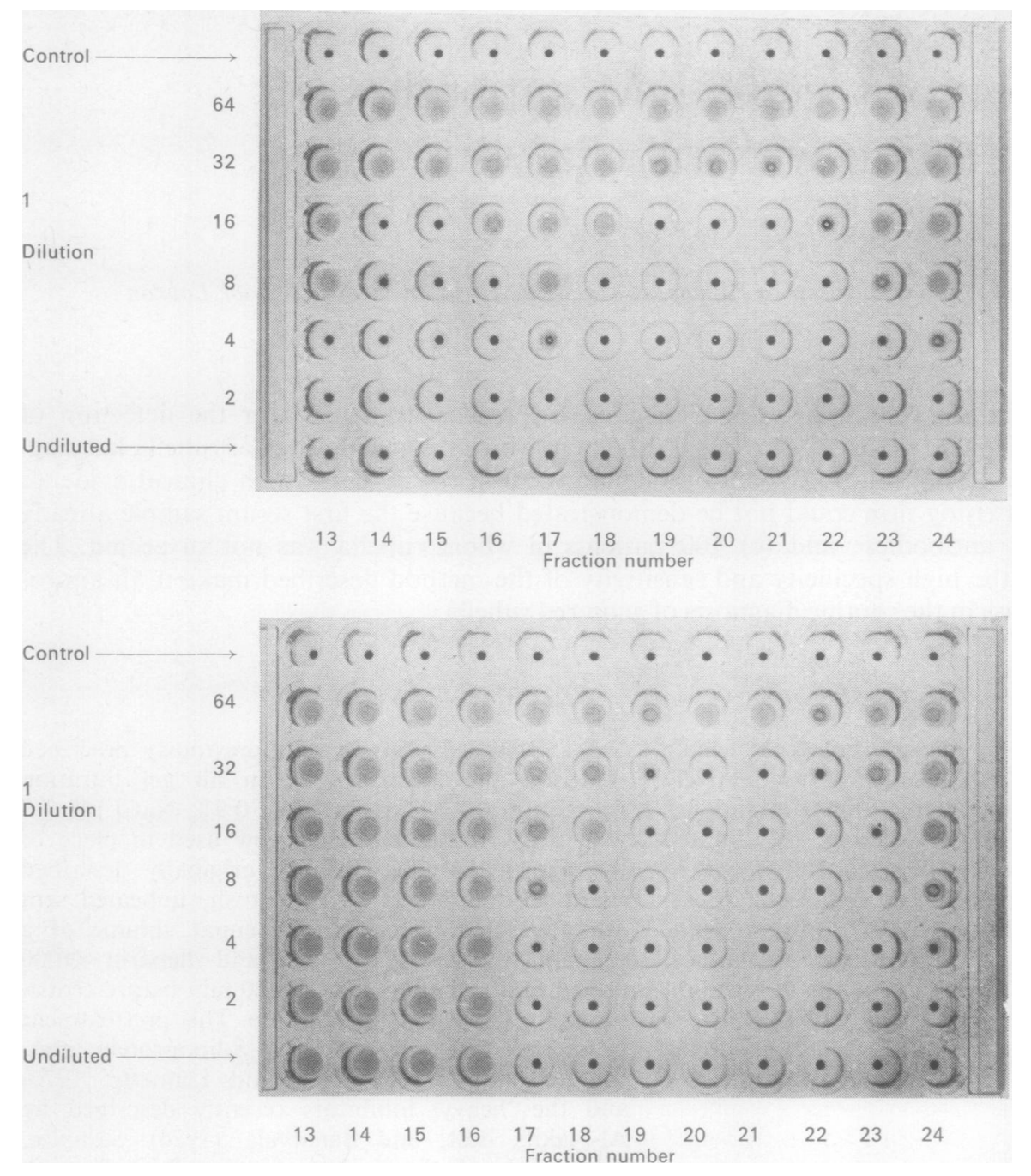

Fig $1 a$ and $b$ Rubella HAI tests of the immunoglobulincontaining fractions eluted from a column of Sephadex G-200 (for explanation see text).

serum. The rubella HAI activity elutes in two peaks whereas with sera from patients with no recent history of a rubella-like illness or contact with rubella all the rubella HAI activity elutes in the second peak (fig $1 \mathrm{~b}$ ).

A quantitative representation of the results can be derived as follows. The total recovery of rubella HAI activity from the column can be calculated by adding together the reciprocal titres of all the fractions and multiplying by 20 to allow for the dilution during the pretreatment and fractionating procedures. In fig $1 \mathrm{a}$ the value obtained is 2420 and in fig $1 \mathrm{~b}$ it is 3200 . Before fractionation both sera had HAI titres of 1 in 2560 . With early convalescent sera the column recovery can be subdivided into two peaks and in fig la the peak 1 recovery (fractions 13-16) is 880 . It is this value which is subsequently referred to as 'reciprocal peak 1 rubella HAI titre'. Alternatively, the rubella HAI activity eluting in peak 1 can be expressed as a percentage of the total HAI activity eluted from the column. In fig $1 \mathrm{a} 36 \%$ of the rubella HAI activity elutes in peak 1 .

\section{Results}

The origins of the sera tested in this study are shown in table I. These were obtained from 115 patients who on clinico-epidemiological grounds were suspected of having recent rubella. The diagnosis was unequivocably confirmed in $\mathbf{4 5}$ cases by the demonstration of rising rubella HAI titres. 


\begin{tabular}{lrr}
\hline Rubella Infections & $\begin{array}{l}\text { No.of } \\
\text { Patients }\end{array}$ & $\begin{array}{l}\text { No.of } \\
\text { Sera }\end{array}$ \\
\hline With diagnostic rises in HAI titre & 85 \\
Without diagnostic rises in HAI titres & 70 \\
Recent rubella not suspected & 79 \\
\hline
\end{tabular}

Table I Clinical status of patients whose sera were tested for the presence of specific IgM antibodies

${ }^{1}$ Sera with high rubella HAI titres selected from those submitted from antenatal and staff health clinics for routine screening for antibodies against rubella.

The early sera necessary for the demonstration of rising titres are not consistently available in routine clinical practice. Therefore the 70 cases in which such rises could not be demonstrated because the first sera already had high titres of antibody are included for comparison. At least one convalescent serum from all 115 cases had specific rubella IgM antibody. Full clinical and epidemiological details of these patients will be described elsewhere.

As a control a further 100 sera were fractionated. These were high-titre sera submitted for routine screening for antibodies against rubella from individuals not suspected of having recent rubella.

RUBELLA HAI ANTIBODIES IN

UNFRACTIONATED SERA

The rubella HAI titres of the 161 unfractionated sera from the 115 cases of clinical rubella are shown in figure 2 . Usually rubella HAI antibodies have been found to develop very soon after the onset of the rash. In one case the titre was already 1 in 640 the day after the rash commenced and a titre of 1 in 2560 was recorded in another case three days after the onset of the rash. On the other hand, in another case no rubella HAI antibodies were detectable seven days after the onset of the rash, the titre being 1 in 1280 seven days later. All sera taken between 10 and 20 days after the onset of the rash have a titre of 1 in 640 or greater.

It is not possible to obtain a good estimate of the rate of appearance of antibodies unless daily specimens are taken in the first few days after the onset of the rash. However, some idea of the potential rate of rise can be derived from those pairs of sera in which both specimens have been taken within the first 10 days. From 12 such pairs the fastest doubling time of the total rubella HAI titre was found to be in 15 hours.

\section{RUBELLA HAI ANTIBODIES AFTER} FRACTIONATION

The peak 1 rubella HAI activity of the 82 sera from the 45 cases confirmed on the basis of rising antibody titres is illustrated in figure 3 . The continu-

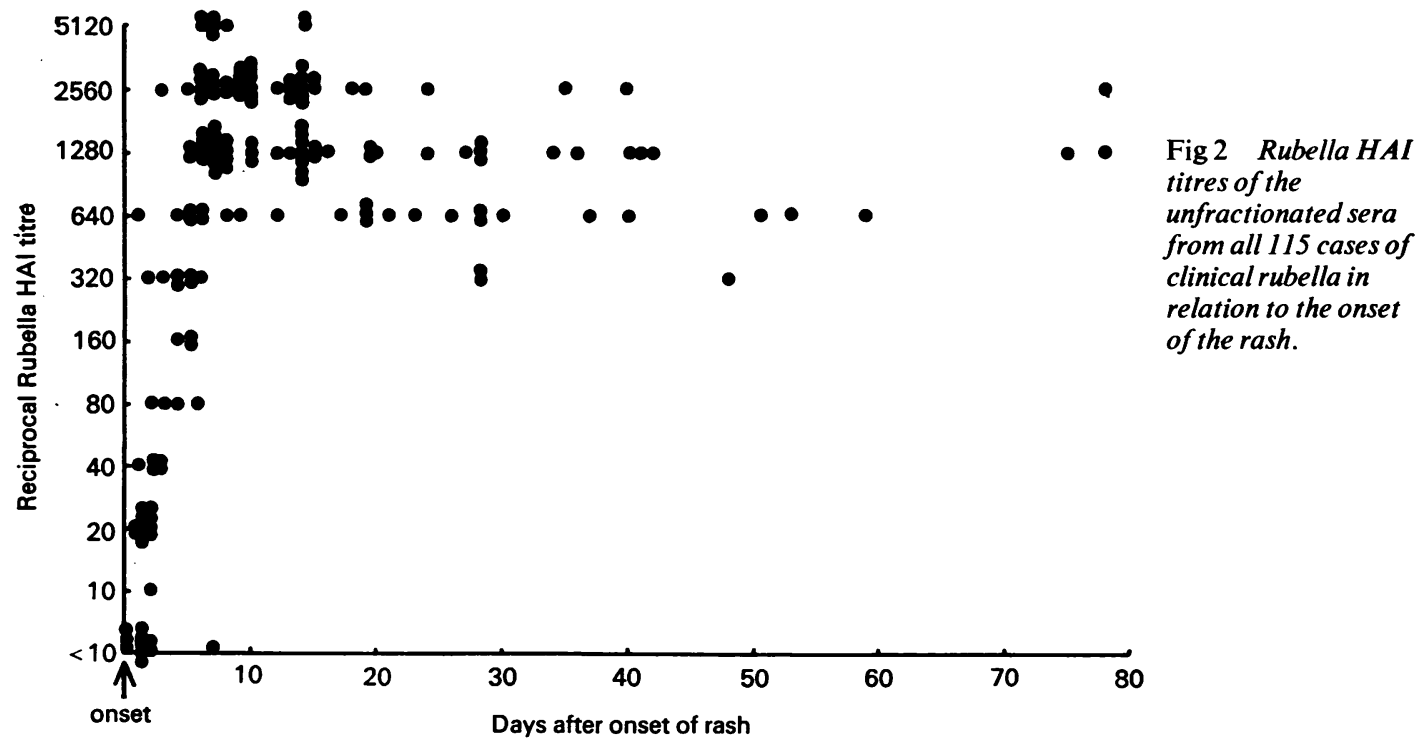




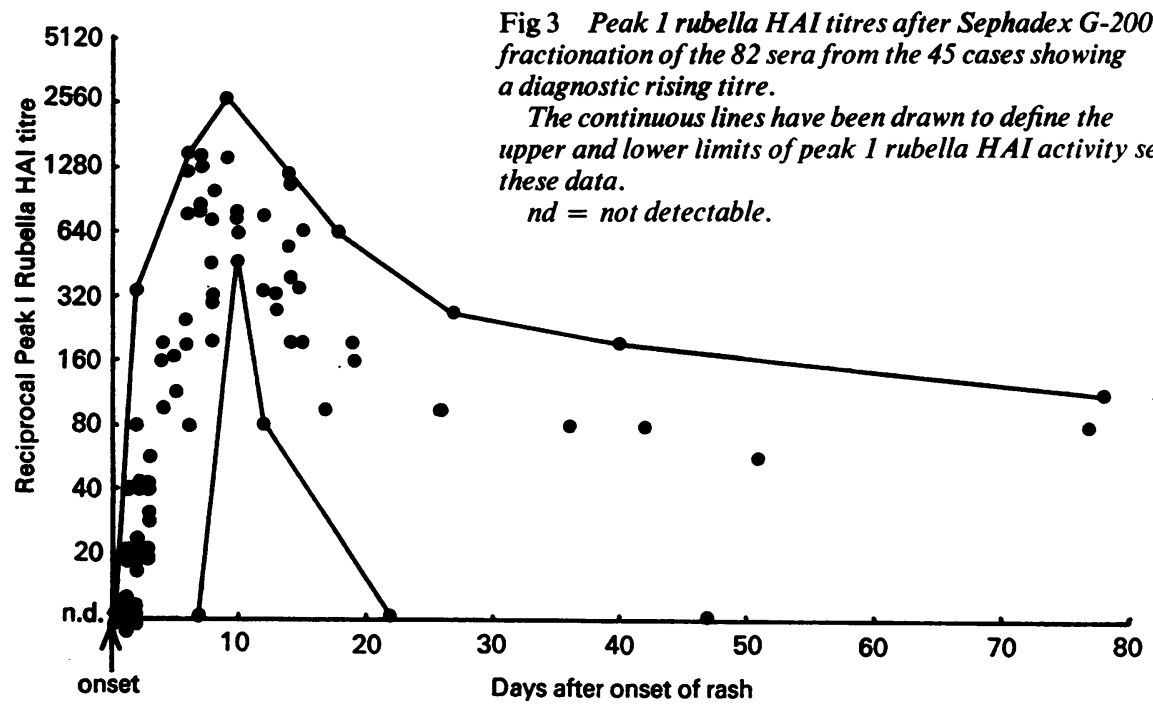

Fig 4 Peak 1 rubella HAI titres after Sephadex G-200

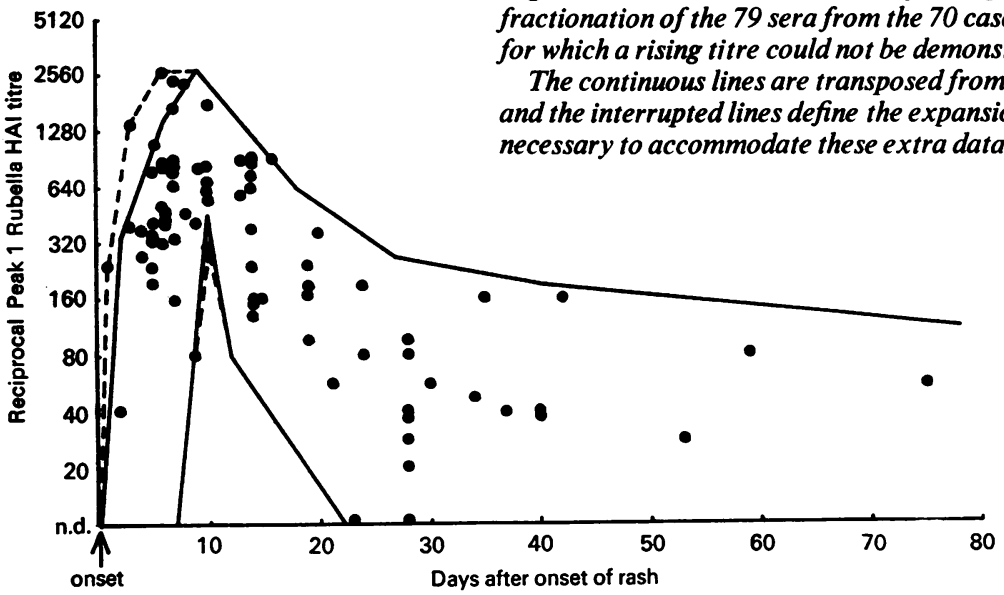

ous lines in this figure define the upper and lower limits of the peak 1 rubella HAI activity set by the data from these 45 cases. An essentially similar set of data was obtained with the 79 sera from the 70 patients in whom a diagnostic rising titre could not be demonstrated (fig 4). Indeed, if the data from these latter 70 cases are included then the limits set by the first 45 cases only need to be expanded slightly to accommodate the relatively high titres of four early sera. Figure 5 shows the peak 1 activity of all 161 sera expressed as a percentage of the total rubella HAI activity.

In general a high percentage (up to 100) of any rubella HAI activity of sera taken within the first few days of the rash elutes in peak 1 . In a number of cases it is possible to demonstrate that peak 1 activity (containing IgM) appears before peak 2 activity (IgG). There were 50 cases in which a serum taken within the first six days of the onset of the rash had a titre of 1 in 20 or greater. In 16 of the 22 sera taken within the first three days of the onset of the rash all the rubella HAI activity eluted in peak 1 after Sephadex G-200 fractionation (fig 6). It is only on the fourth and subsequent days after the onset of the rash that specific rubella IgG (peak 2 activity) can be detected in the majority of sera (fig 6). Even so, in one case there was no detectable specific IgG antibody in a serum taken 


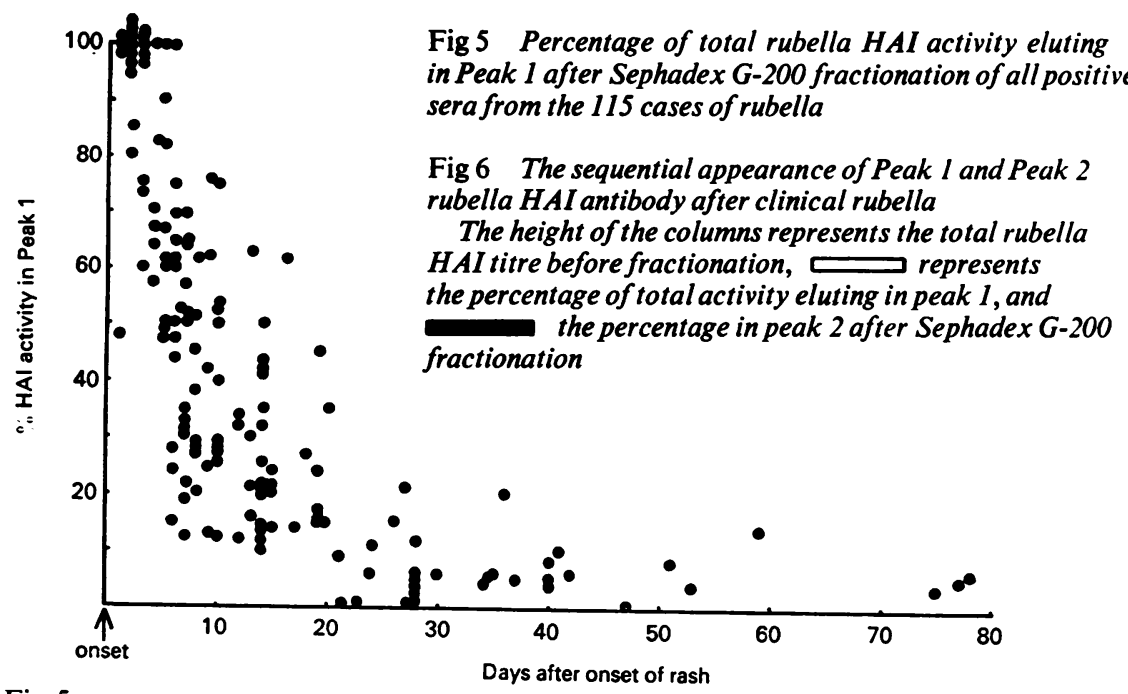

Fig 5

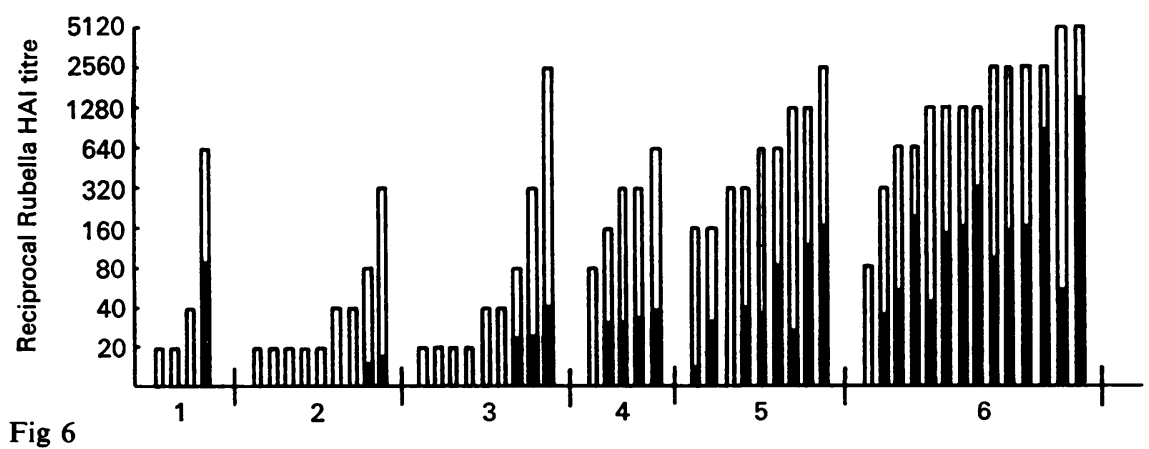

Days after onset of rash

on the fifth day after the appearance of the rash, and in another case none in a serum taken on the sixth day afterwards (fig 6).

In order to validate the association of peak 1 rubella HAI activity with relatively recent rubella, sera with high rubella HAI titres from individuals not suspected of having recent rubella were examined for specific IgM. Out of 100 such sera only one was found to contain rubella HAI antibody which fractionated in peak 1 . This serum had a rubella HAI titre of 1 in 1280 and $10 \%$ of this fractionated in peak 1. On questioning the patient (a nurse who had just commenced training), it was revealed that five weeks previously she had had a rash with cervical lymphadenopathy which had been diagnosed on clinical grounds as rubella.

\section{Discussion}

In devising the gel filtration technique used here particular attention was paid to maintaining simplicity and low cost (Pattison and Mace, 1973). With only minor modifications (see Materials and Methods) the technique has been applied to the diagnosis of acquired rubella in a routine clinical laboratory for almost three years. For this purpose the entire procedure involves only a basically standard pretreatment of serum, filtration through a column of Sephadex G-200, and finally routine rubella HAI testing of 12 of the eluted fractions. The validity of this procedure as a diagnostic technique for rubella is based on the results described here.

Sephadex G-200 fractionation of the first convalescent serum from those 45 cases in which a rising titre could be demonstrated indicated that some of the activity of all such sera except one eluted in peak 1 (fig 3). The exception was a case in which the convalescent specimen was not taken until 47 days after the start of the rash. Confirmation 
of the diagnosis in the remaining 70 cases in which a rising titre could not be demonstrated has been based solely on the demonstration of peak 1 activity after gel filtration with Sephadex G-200. The peak 1 rubella HAI titres of only four of the sera from these 70 cases are outside the limits set by the sera from the 45 cases in which a rising titre could be demonstrated. All four sera were taken within the first week after the onset of the rash and all had high rubella HAI titres relative to other sera taken at a similar stage after the onset of the rash. Two cases with high rubella HAI titres within the first two days after the onset of the rash have been described (Cradock-Watson and Hambling, 1973). In both, the high titres were substantially due to antibody of the IgM class.

In contrast to the above, a search for peak 1 rubella HAI antibody among 100 high-titre $(>1$ in $640)$ sera revealed only one positive and on retrospective enquiry it was learned that this serum was from a patient who had had a typical rubella-like illness five weeks previously.

These findings are in agreement with those of Gupta et al (1971) in confirming the association between rubella virus infection and the occurrence of peak 1 rubella HAI activity in convalescent sera. These authors take the rubella HAI titre of the pooled fractions contributing to the ascending limb of the first protein peak as an expression of the specific IgM content of a serum. This will largely avoid contamination with specific high molecular weight IgA since this elutes in the latter half of peak 1. However, the studies described here indicate that the entire peak 1 rubella HAI activity is related to recent infection. Moreover, Bio-Gel A-5M fractionation of 95 sera from 65 of the cases described here give results in agreement with those of BürginWolff et al (1971) showing that the appearance and disappearance of specific rubella antibody of the high molecular weight $\operatorname{IgA}$ class is closely related to recent infection (Pattison and Mace, to be published). Indeed in only one out of the 95 sera so tested was specific high molecular weight IgA present in the absence of specific IgM. Therefore for routine diagnostic purposes no distinction need be made between these two types of antibody, and the entire peak 1 activity after Sephadex G-200 fractionation may be taken as an index of recent infection.

The titres of the peak 1 activity after Sephadex G-200 fractionation found in the sera from the 115 cases described vary quite markedly. Clearly this is partly due to a variation linked to the time after the onset of the rash at which sera were taken, but partly also to a true individual variation in peak 1 titre of sera taken at a given time after the $\overrightarrow{\vec{F}}$ rash. It seems unlikely from the experience gained with the cases described that any case will be $\frac{C}{0}$ missed because of failure to detect peak 1 activity $\frac{\bar{\sigma}}{\bar{c}}$ if a serum taken seven to 14 days after the onset of $\overrightarrow{\widetilde{D}}$ the rash is available for testing. Apart from one $\stackrel{\varrho}{0}$ case with a serum taken seven days after the rash के with a total rubella HAI titre of less than 1 in $10 \overrightarrow{0}$ (a subsequent rise in titre to 1 in 1280 being demon- $\vec{\overrightarrow{ }}$ strated with a serum taken 14 days after the appearance $\vec{\omega}$ of the rash), all sera taken seven to 14 days after the rash appeared had a total rubella HAI titre of at least 1 in 640 .

In such sera the lowest peak $1 \mathrm{HAI}$ titre recorded was 1 in 80 which was found in a serum taken $y$ nine days after the onset of the rash in one case ${ }_{0}$ and 12 days after the onset of the rash in another case, the diagnosis of rubella in the latter case $\bar{z}$ having been confirmed by the demonstration of a rising titre of rubella HAI antibodies. Because of $\vec{\omega}$ the 1 in 20 dilution in the gel filtration procedure this appeared in the actual test as a titre of 1 in $2^{\mathrm{N}}$ in two of the four fractions contributing to the first protein peak (peak 1). Thus a fourfold diminution in peak 1 titre would be necessary before peak $1 \overline{0}$ rubella HAI activity was not detectable in such sera.

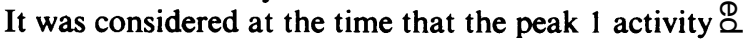
might still be rising in these cases but in a serum $\overrightarrow{\overrightarrow{0}}$ taken 22 days after the onset of the rash in one case 3 and 23 days after in the other no rubella HAI activity was detectable in peak 1 at all.

Thus with the balance of sample and fraction size described and long reaction time when testing the HAI fractions, a technique of high specificity and appropriate sensitivity has resulted without the necessity of concentrating samples or pooling and/or concentrating fractions.

\section{References}

Al-Nakib, W., Best, J. M., and Banatvala, J. E. (1974). Rubellaspecific IgM and a new inhibitor. Brit. mod. J., 2, 579.

Bürgin-Wolf, A., Hernandez, R., and Just, M. (1971). Separation of rubella IgM, IgA and IgG antibodies by gel filtration on $\mathrm{N}$ agarose. Lancet, 2, 1278-1280.

Cradock-Watson, J. E., and Hambling, M. H. (1973). Serological diagnosis of acute rubella. Communicable Disease Report, $73 / 26,1$.

Gupta, J. D., Peterson, V., Stout, M., and Murphy, A. M. (1971). $\stackrel{\mathcal{D}}{\mathcal{C}}$ Single sample diagnosis of recent rubella by fractionation of antibody on Sephadex G-200 column. J. clin. Path., 24, 547- $\square$ 550.

Pattison, J. R., and Mace, J. E. (1973). A simple, inexpensive gel $\stackrel{\vec{D}}{\circ}$ filtration technique for use in diagnostic serology. J. clin. $\triangle$ Path., 26, 309-311.

Schmidt, N. J., and Lennette, E. H. (1970). Variables of the rubella $\stackrel{\mathbb{D}}{\mathrm{Q}}$ hemagglutination-inhibition test system and their effect on $\sigma$ antigen and antibody titers. Appl. Microbiol. 19,491-504. 